\title{
Measurement of acute phase proteins for assessing severity of Plasmodium falciparum malaria
}

\author{
S H Gillespie, C Dow, J G Raynes, R H Behrens, P L Chiodini, K P W J McAdam
}

\begin{abstract}
Seventeen adult patients with acute Plasmodium falciparum malaria, admitted to the Hospital for Tropical Diseases, were studied. Serial measurements of the serum concentration of $C$ reactive protein, serum amyloid $A$ protein, and percentage parasitaemia were determined, together with initial measurement of serum electrolytes, liver function, haemoglobin, white cell and platelet counts. Initial C-reactive protein and serum amyloid $A$ concentrations were increased (C-reactive protein mean $49.0 \mathrm{mg} / 1$ serum amyloid $A 28 \mathrm{mg} /$ 1) falling towards the normal range by the seventh day of treatment. There was a significant correlation between the pretreatment parasite count and clinical and laboratory markers of inflammation. C-reactive protein and serum amyloid $A$ concentrations correlated inversely with the serum sodium.

These results indicate that measurement of acute phase reactants such as Creactive protein and serum amyloid $A$ may prove valuable in assessing the severity of $P$ falciparum malaria, and in following the response to antimalarial treatment.
\end{abstract}

The pathophysiological response to infection with $P$ falciparum is highly variable. It depends on several different factors including previously acquired immunity and the production of cytokines such as interleukin-1 (IL-1) and tumour necrosis factor (TNF), $\gamma$-interferon $(\gamma$-IFN), and interleukin-6 (IL-6). Secretion of these mediators is thought to be responsible for many of the clinical features of malaria. ${ }^{1-6}$

Clinical assessment of severity depends on bedside observation of variables such as blood pressure, fever, and mental alertness. These can be supplemented by routine laboratory measurements. The degree of parasitaemia is correlated with severity of disease and falls in serum sodium and albumin are often found in more severely ill patients. ${ }^{7}$

C-reactive protein is a pentameric protein molecule which has been conserved over a long period of evolution. It binds to phosphorylcholine epitopes found in Streptococcus pneumoniae and many parasites. Binding results in activation of the classical complement pathway. Serum amyloid $A$ is the precursor of amyloid A protein found in the amyloid fibrils present in secondary amyloid deposits. Both proteins increase in concentration in the serum up to 1000 times in response to inflammatory stimuli, whether infective or traumatic. $^{8}$

Measurement of acute phase reactants like C-reactive protein or serum amyloid $A$ has been used to monitor the response to antibacterial treatment. Increased concentrations of C-reactive protein have also been used to distinguish acute pyogenic from viral meningitis. ${ }^{9}$ Although the stimulus to acute phase reactants production is not fully understood, macrophage derived cytokines including IL-6, TNF, and IL-1 are thought to be important. $^{10}$

Measurement of cytokines has been used in studies of malaria in children in the Gambia and Malawi $^{211}$ and adults in Germany. ${ }^{4}$ Measurement of cytokine concentration is not usually available in clinical laboratories. The very short half-life of cytokines in serum makes assay of these substances difficult to interpret in clinical practice. This study was designed to test whether measurement of acute phase reactants as an indirect measure of cytokine concentration would prove valuable in assessing the severity of malaria compared with standard laboratory markers, and whether sequential measurement would be valuable in assessing response to antimalarial treatment.

\section{Methods}

Seventeen patients with uncomplicated acute $P$ falciparum malaria, admitted to the Hospital for Tropical Diseases, London, were studied. Twelve were men and five women. Twelve were of European origin, four were African, and one was from the Indian subcontinent. Sixteen of the patients acquired their infection in Africa and one in the Far East. Malaria was the only diagnosis in each case and all were successfully treated with intravenous or oral quinine followed by three tablets of Fansidar.

The following laboratory investigations were performed on the day of admission: percentage parasite count, differential white cell count, measurement of the haematological indices including platelet count, together with measurement of serum electrolytes, bilirubin, and liver enzyme concentrations. The patient's maximum temperature was recorded. Blood was drawn daily and a percentage parasite count performed. C-reactive protein and serum amyloid $\mathrm{A}$ were measured on daily 
Figure Serum concentrations of $C$ reactive protein and serum amyloid $A$ in 17 patients with acute $P$ falciparum malaria. Mean value indicated by solid line.

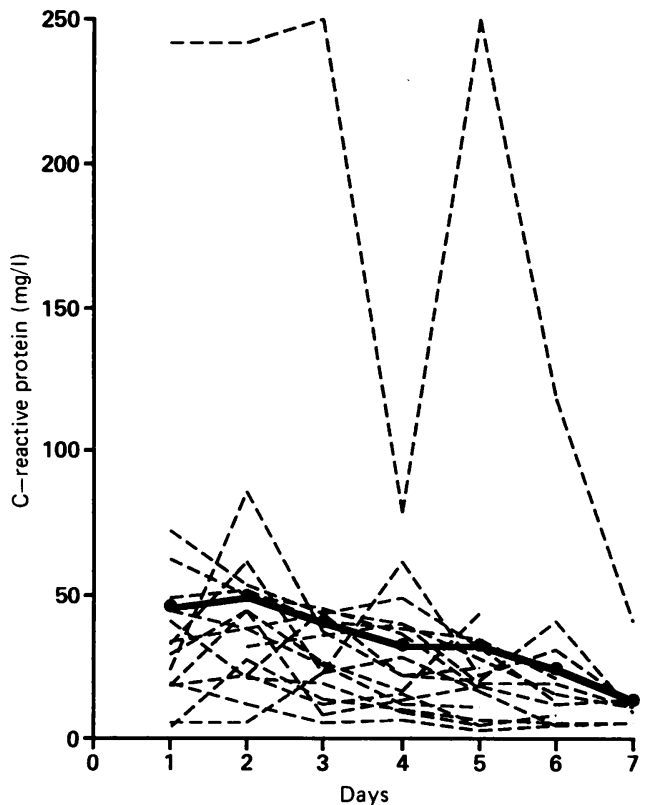

serum samples using a competitive enzyme linked immunosorobent assay (ELISA) technique.

Immulon 2 (Dynatech) microtitre plates were coated with affinity purified antibodies to human C-reactive protein and serum amyloid $A$ (derived in rabbit and goat, respectively) by incubation overnight at $4^{\circ} \mathrm{C}$ in bicarbonate buffer (pH 9.2). Serum specimens were diluted in phosphate buffered saline with $0.05 \%$ Tween-20 (pH 7.5) (PBS-Tween). Diluted sample $(100 \mu \mathrm{l})$ was added to a microtitre well together with $100 \mu \mathrm{l}$ of alkaline-phosphatase conjugated C-reactive protein or serum amyloid $A$ and incubated for one hour at room temperature in a humidified chamber. The optimal concentration for all of the reagents was previously determined by chequerboard titration. After washing the plates p-nitrophenyl phosphate substrate was added, and the resulting colour change measured using a Dynatech 600 ELISA reader at $405 \mathrm{~nm}$. The concentration of Creactive protein or serum amyloid $A$ present in the sample was determined by calculation from a series of standard concentrations of highly purified C-reactive protein or high density lipoprotein (HDL) tested in parallel on the same plate.

\section{Results}

Fifteen of the 17 patients had raised concentrations of C-reactive protein $(>10 \mathrm{mg} / \mathrm{l})$ and

Table 1 Mean values of parasitological, haematological, and biochemical variables measured in 17 patients presenting with acute P falciparum malaria

\begin{tabular}{lccc}
\hline Investigation & Mean & Range & $S E M$ \\
\hline C-reactive protein & $46 \cdot 1$ & $(3 \cdot 4-242 \mathrm{mg} / \mathrm{l})$ & $14 \cdot 8$ \\
Serum amyloid A & $28 \cdot 8$ & $(1 \cdot 4-158 \mathrm{mg} / \mathrm{l})$ & $8 \cdot 7$ \\
Sodium & 136 & $(126-141 \mathrm{mmol} / \mathrm{l})$ & $0 \cdot 9$ \\
Bilirubin & 22.5 & $(8-60 \mathrm{mmol} / \mathrm{l})$ & $3 \cdot 24$ \\
Albumin & $39 \cdot 8$ & $(35-47)$ & $1 \cdot 02$ \\
White cell count & $5 \cdot 5$ & $(3 \cdot 3-7 \cdot 8)$ & $0 \cdot 3$ \\
Platelets & $159 \cdot 6$ & $(59-327)$ & $19 \cdot 74$ \\
Maximum temperature & $38 \cdot 3$ & $(36-40 \cdot 2)$ & $0 \cdot 28$ \\
Percentage parasitaemia & 1 & $<0 \cdot 1-4 \cdot 8 \%$ & $0 \cdot 33$ \\
\hline
\end{tabular}

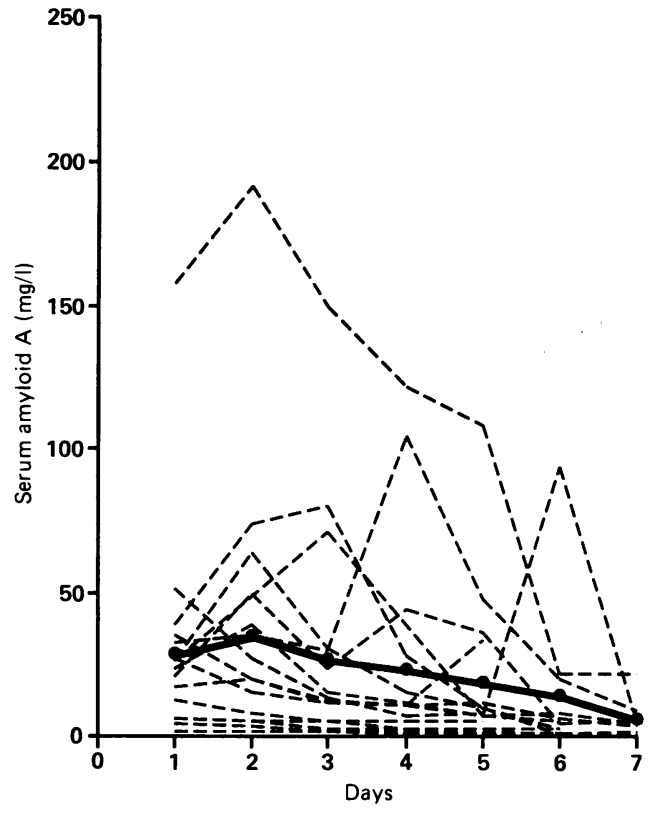

serum amyloid $\mathrm{A}$ ( $>4 \mathrm{mg} / \mathrm{l}$ ) on presentation. The mean concentration of both acute phase reactants increased on the second day of treatment, then fell slowly over the next five days. Individual values show variation but with a general downward trend in parallel with the disappearance of parasites from the peripheral blood and clinical recovery. The results for all patients are shown in the figure.

No patients had gross abnormality of biochemical and haematological indices, although several had increased bilirubin concentrations and decreased serum sodium. This was consistent with the clinically mild course of the infection in this patient group. The mean of all results, together with range and standard error of mean, are recorded in table 1.

Correlation was sought between serum concentration of acute phase reactants C-reactive protein and serum amyloid $\mathrm{A}$ and the conventional marker of malaria severity-parasite count, and with haematological and biochemical variables. There was no correlation between the peripheral white cell count and any other variable measured. A significant positive correlation was found between percentage parasite count and acute phase protein concentrations. There was a highly significant inverse correlation between serum sodium, the maximum temperature, the parasite count and the concentration of acute phase reactants. A significant positive correlation was also found between the maximum temperature and the concentration of $\mathrm{C}$-reactive protein and serum amyloid $\mathrm{A}$, and with serum bilirubin concentration. These results are summarised in table 2.

\section{Discussion}

The methods used to assess objectively the severity of $P$ falciparum malaria on admission, and the response to antimalarial chemotherapy are unsatisfactory. ${ }^{12}$ Severity can be assessed by evaluating a combination of clinical observations including height of fever, disturbance of 
Table 2 Summary of correlation coefficients between laboratory markers of severity in 17 patients with acute $P$ falciparum malaria

\begin{tabular}{|c|c|c|c|c|c|c|c|c|}
\hline & Sodium & $\begin{array}{l}\text { Maximum } \\
\text { temperature }\end{array}$ & $\begin{array}{l}\text { White cell } \\
\text { count }\end{array}$ & Parasitaemia & Albumin & Bilirubin & Platelets & $\begin{array}{l}C \text {-reactive } \\
\text { protein }\end{array}$ \\
\hline $\begin{array}{l}\text { Serum amyloid A } \\
\text { C-reactive protein } \\
\text { Platelets } \\
\text { Bilirubin } \\
\text { Albumin } \\
\text { Parasitaemia } \\
\text { White cell count } \\
\text { Maximum temperature } \\
\text { Sodium }\end{array}$ & $\begin{array}{l}-0.735^{\star \star \star} \\
-0.802^{\star \star \star} \\
-0.077 \\
-0.124 \\
0.456 \\
-0.831^{\star \star \star} \\
-0.008 \\
-0.667^{\star \star \star}\end{array}$ & $\begin{array}{l}0 \cdot 545^{\star} \\
0 \cdot 588^{\star} \\
0 \cdot 163 \\
0 \cdot 539^{\star} \\
-0 \cdot 292 \\
0 \cdot 617^{\star \star} \\
-0.013 \\
-\end{array}$ & $\begin{array}{l}0 \cdot 142 \\
0 \cdot 104 \\
0 \cdot 182 \\
0 \cdot 340 \\
-0 \cdot 243 \\
0 \cdot 105 \\
= \\
=\end{array}$ & $\begin{array}{l}0 \cdot 713^{\star \star \star} \\
0 \cdot 676^{\star \star} \\
0 \cdot 014 \\
0 \cdot 226 \\
-0 \cdot 334 \\
= \\
= \\
-\end{array}$ & $\begin{array}{l}-0 \cdot 105 \\
-0 \cdot 134 \\
-0.012 \\
0 \cdot 204 \\
= \\
= \\
=\end{array}$ & $\begin{array}{l}0.448 \\
0.336 \\
-0.019 \\
= \\
= \\
= \\
=\end{array}$ & $\begin{array}{l}-0 \cdot 178 \\
-0 \cdot 238\end{array}$ & $\underline{-}^{0.949 \star \star \star}$ \\
\hline
\end{tabular}

conscious level, hypotension, or detecting other signs indicating the development of complications. Laboratory markers have also been studied, and severity of malaria has been associated with higher parasitaemia, a fall in serum sodium and albumin concentration, low platelet counts and a rise in serum bilirubin and urea concentrations. Measurements of parasitaemia have drawbacks as markers of severity as semi-immune people may tolerate levels of parasitaemia which would be associated with severe disease in non-immune subjects. The study reported here used nonimmune subjects with mild to moderate infection, in whom malaria was the only diagnosis, to reduce non-specific confouding effects.

Recent research has confirmed the importance of leucocyte mediators such as TNF in the pathogenesis of severe malaria. Even in severe disease cytokine concentrations remain in the picogramme per $\mathrm{ml}$ range. This low concentration is coupled with a short plasma half-life, making measurement difficult in the clinical setting. A study of TNF concentrations in 75 Gambian children with acute $P$ falciparum malaria failed to show a correlation between the concentration of TNF and severity of disease, although increased TNF concentrations were found more often in patients with complications. ${ }^{2}$ In a study in Germany of patients with $P$ falciparum and $P$ vivax, however, serum IL-6, measured using a bioassay and TNF measured by ELISA, was shown to be correlated with the presence of severe complications. Moreover, serum concentrations fell in response to antimalarial chemotherapy. ${ }^{4}$ In a study of 65 children with severe $P$ falciparum malaria in Malawi the mean initial serum concentration of TNF was significantly higher in the 10 patients who died than in the 55 who survived. ${ }^{12}$ High concentrations of TNF were also associated with hypoglycaemia, hyperparasitaemia, and severity of illness as measured by a prognostic index.

A secondary consequence of cytokine production is the stimulation of the acute phase reaction. Studies of sequential acute phase reactants concentrations have been correlated with severity of bacterial infection and therapeutic reponse to specific antibacterial treatment.

This pilot study shows significant correlations between conventional laboratory markers of severity of malaria-parasite count, serum sodium and albumin - with acute phase reac- tants. This may be of value in supporting the clinical assessment of patients and in more accurately classifying patients being entered into clinical trials.

Current methods for assessing the response to antimalarial chemotherapy are imprecise. ${ }^{12}$ Several different variables have been used. Parasite clearance time is widely accepted, but it is comprised by the sensitivity of the test and observer error. ${ }^{13}$ Studies vary in their definition of parasite clearance time, some choosing the time to the last positive slide and others the time to the first negative slide. Observer errors are particularly important in studies of mild malaria when parasite numbers are low. Other measures which have been used in the assessment of chemotherapy include mortality as an end point. It has been shown, however, that the use of death as an end point would require very large patient numbers to show a significant difference between regimens. ${ }^{12}$ Other clinical measures of therapeutic response include time to abatement of fever, but accurate consistent measurement of fever is difficult in large studies. Complex manipulations of fever data are compromised by the initial difficulty of obtaining consistent data. It is therefore difficult to compare fever data among different studies.

It has been suggested that laboratory variables which show improvement in response to treatment, such as urea, glucose, platelet count, etc, would be valuable in the assessment of response to antimalarial chemotherapy but this possibility has not been shown in prospective studies.

Each of the patients in this study showed a consistent fall in acute phase reactant concentrations over the period of antimalarial treatment. Although individual values could vary, sometimes increasing, there was a consistent downward trend. The concentrations of acute phase reactants were found to be increased on the second day of the hospital admission in all patients studied; this is consistent with an increase in parasitaemia which occurs commonly up to 18 hours after starting antimalarial chemotherapy.

These data support the idea that sequential measurement of acute phase reactant concentrations are valuable in the assessment of the clinical course of patients with acute $P$ falciparum malaria. Clinicians monitoring treatment in this way must be alert to the variation which occurs and observe the overall trend. 
Such measurements have physiological relevance as they are an indirect measure of inflammatory mediators thought to be important in the pathogenesis of the disease. Consequently, measurement of acute phase reactant concentrations are likely to be more objective than clinical observation in a clinical trial setting. We would expect, therefore, that the use of sequential measurement of acute phase reactants as a means of assessing response to chemotherapy will result in more reproducible results among different centres and among trials.

Dr SH Gillespie was supported by a Clinical Lectureship from the Mercers Company of London. The authors acknowledge the support of the Wellcome Trust and the Arthritis and Rheumatism Council.

1 Scuderi P, Sterling K, Lam KS, et al. Raised serum levels of tum necrosis factor in pasitic infections. Lancet 1986;ii:1364-5.

2 Kwiatkowski D, Cannon JG, Manogue KR, Cerami A, Dinarello CA, Greenwood BM. Plasma levels and mononuclear cell production of tumour necrosis factor in falciparum malaria. Clin Exp Immunol 1989;77:361-6.
3 Keru P, Hemmer CJ, Van Damme J, Gruss H-J, Dietrich M. Elevated Tumor Necrosis Factor alpha and interleukin-6 serum levels as markers for complicated Plasmodium falciparium malaria. Am J Med 1989;87:139-43.

4 Clark IA. Cell mediated immunity in protection and path ology of malaria. Parasitology Today 1987;3:300-5

5 Grau GE, Piguet PF, Vassalli P, Lambert PH. Tumor necrosis factor and other cytokines in cerebral malaria: experimental and clinical data. Immunol Rev 1989;112. 49-70.

6 Grau GE, Piguet PF, Vassalli P, Lambert PH. Involvement of tumour necrosis factor and other cytokines in immune mediated vascular pathology. Int Arch Allergy Appl Immunol 1989;88:34-9.

7 Hall AP. The treatment of severe falciparium malaria. Trans $R$ Soc Med Hyg 1975;71:367-79.

8 Pepys MB. Acute phase proteins with special reference to C-reactive protein and related proteins (pentaxins) and serum amyloid A protein. Adv Immunol 1983;34:141-212.

9 deBeer FC, Kirsten GF, Gie RP, Beyers N, Strachan AF Value of C-reactive protein measurement in tuberculous, bacterial and viral meningitis. Arch Dis Child 1984 59:653-6.

10 Gauldie J, Richards C, Harnish D, Lansdorp P, Baumann H. Interferon B2/B cell growth factor type 2 shares identity with monocyte derived hepatocyte stimulating factor and (n) Natl Acad Sci USA 1987;84:7251-6.

11 Grau GE, Taylor TE, Molyneux ME, et al. Tumor necrosis factor and disease severity in children with falciparum factor and disease severity in children

12 White NJ, Krishna S. Treatment of malaria: some conWhite NJ, Krishna S. Treatment of malaria: some con-
siderations and limitations of the current methods of siderations and limitations of the current methods
assessment. Trans R Soc Med Hyg 1989;83:767-77.

13 Bruce-Chwatt LJ. (editor) Chemotherapy of malaria. $2 \mathrm{nd} \mathrm{Ed}$ Geneva: World Health Organisation, 1981. 